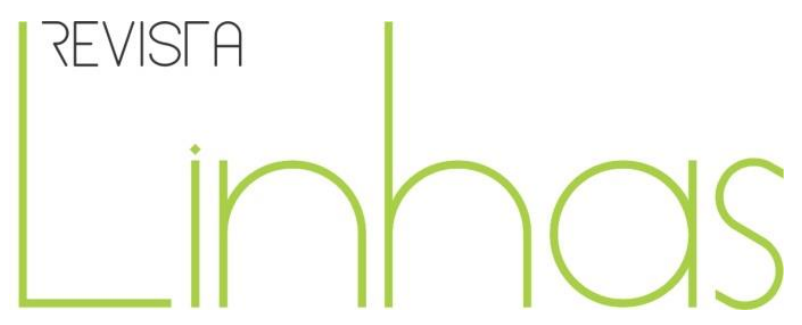

\title{
Formação de professores frente ao desafio da diversidade pela lente omnilética: culturas, políticas e práticas em movimento
}

\begin{abstract}
Resumo
Em 2015, o Observatório Estadual de Educação Especial no Rio de Janeiro (OEERJ) desenvolveu a pesquisa colaborativa intitulada Formação de Professores para a Inclusão do público-alvo da Educação Especial - refletindo, planejando e agindo. O objetivo geral, tanto da pesquisa quanto do curso de extensão, foi identificar e discutir temas considerados relevantes pelos participantes, no que tange à valorização da diversidade e para o desenvolvimento de culturas, políticas e práticas inclusivas, visando à participação e aprendizagem de todos os alunos no dia a dia escolar, tendo por material de base o Index para a Inclusão (BOOTH; AINSCOW, 2011). Esse processo nos colocou diante do desafio de proporcionar a articulação entre professores do Atendimento Educacional Especializado e do ensino regular no que tange a estratégias de inclusão em educação; promover e avaliar estratégias de participação dos professores na pesquisa, por meio de 10 encontros de formação, com duração de sete horas aos sábados; e desenvolver práticas pedagógicas de inclusão, a partir de situações cotidianas que desafiam a valorização da diversidade em sala de aula. Durante o processo de formação foram elencados pelos participantes cinco principais temas: acessibilidade, avaliação, currículo, formação e políticas, que serão argumentados e analisados neste breve relato de experiência sob a perspectiva omnilética (SANTOS, 2013). Dentre os resultados desta pesquisa, destacamos a importância de despertar o potencial protagonista da ação docente para a elaboração de estratégias pedagógicas próprias, que, intencionalmente, promovam o debate, a identificação e a valorização das diferenças, assim como a eliminação das barreiras à inclusão em educação.
\end{abstract}

Palavras-chave: Formação de Professores. Perspectiva Omnilética. Diversidade.

\section{Para citar este artigo:}

DOS SANTOS, Mônica Pereira; SANTIAGO, Mylene Cristina; DE MELO, Sandra Cordeiro. Formação de professores frente ao desafio da diversidade pela lente omnilética: culturas, políticas e práticas em movimento. Revista Linhas. Florianópolis, v. 19, n. 39, p. 11-29, jan./abr. 2018.

DOI: 10.5965/1984723819392018011

http://dx.doi.org/10.5965/1984723819392018011

\section{Mônica Pereira dos Santos}

Universidade Federal do Rio de Janeiro - UFRJ - Rio de Janeiro/RJ - Brasil monicapes@gmail.com

Mylene Cristina Santiago Universidade Federal Fluminense - UFF - Niterói/RJ - Brasil mylenesantiago87@gmail.com

\section{Sandra Cordeiro de Melo}

Universidade Federal do Rio de Janeiro - UFRJ - Rio de Janeiro/RJ - Brasil sandracmello@gmail.com 


\title{
Teacher training in face of the challenge of diversity by means of the omnilectical lense: cultures, policies and moving practices
}

\begin{abstract}
In 2015, the Rio de Janeiro State Observatory of Special Education (OEERJ) carried out a collaborative research named Teacher Education for the inclusion of special education students: reflecting, planning and acting, by means of a continued education course with the same name. The main aim of the research was to investigate and identify themes considered relevant by the participants in valuing diversity and in the development of cultures, policies and practices of inclusion with a view to improving learning and participation of all students in the daily school routine. The course used the Index for Inclusion as basic material (BOOTH; AINSCOW, 2011). Such a process challenged us in different ways: to articulate special education and regular classroom teachers in providing educational inclusion strategies; to promote and evaluate strategies for the participation of teachers in the research over ten 7-hour meetings on Saturdays distributed along the year; to develop inclusive pedagogic practices based on daily situations that challenge the appreciation of diversity in the classroom. Five main topics were chosen by the participants in the training process: accessibility, evaluation, curriculum, teacher education and public policies of inclusion. These will be described and analysed in this article under the omnilectical perspective (SANTOS, 2013). Among the findings, we highlight the importance of awakening the protagonist potential of the teaching activity while elaborating their own pedagogic strategies, which intentionally promote debates, identification and valorisation of the differences, as well as the elimination of barriers to inclusion in education.
\end{abstract}

Keywords: Teacher Education. Omnilectical Perspective. Diversity. 
O estado do Rio de Janeiro, desde 2011, participa do Observatório Nacional de Educação Especial (ONEESP), liderado pela Universidade Federal de São Carlos (UFSCAR). Em nível estadual, o Observatório Estadual da Educação Especial no Rio de Janeiro (OEERJ) é liderado pela Universidade Federal do Rio de Janeiro (UFRJ). Além da UFRJ, dele participam as Universidades Públicas: Federal Fluminense (UFF) e Federal Rural do Rio de Janeiro (UFRRJ).

O OEERJ tem se firmado, a cada ano, por meio de pesquisa colaborativa relativa ao contexto estadual, em que participam professores de atendimento educacional especializado (AEE) e de sala comum em um Ciclo de Formação Continuada que oferecemos a cada ano. Percebendo a fragilidade dos professores no que tange ao processo de formação para o atendimento educacional especializado, temos buscado promover experiências formativas em que os conteúdos e o processo de formação são definidos coletivamente, de modo a articular a experiência dos professores da educação básica com as ações e pesquisas das universidades envolvidas.

Para tanto, temos usado o Index para Inclusão (BOOTH; AINSCOW, 2011) como material balizador das discussões e experiências vivenciadas na formação. O Index para inclusão consiste em um material provocador de reflexão-ação, por meio da análise coletiva de dimensões, indicadores e questões a serem refletidas. Originalmente, ele foi construído para ser desenvolvido em escolas, mas nossa experiência com este material desde o início de sua construção (ano 2000) tem nos proporcionado adaptá-lo a outros contextos educacionais, de forma que podemos afirmar que ele pode ser articulado em quaisquer instituições educativas.

Quanto às dimensões, tratam-se de três: o desenvolvimento de culturas, a construção de políticas e a orquestração de práticas cujos princípios são de inclusão. Culturas são definidas como tudo aquilo que traduz nossos valores construídos e aprendidos ao longo da vida: preceitos, princípios, pontos de partida, perspectivas de vida... Coisas que, enfim, damos como "certas" e defendemos sem nem mesmo percebêlas. Políticas, segundo os autores, referem-se à organização que se promove no cotidiano 
institucional em suporte aos princípios de inclusão. Práticas, por sua vez, são o que se é, o que se faz, o que se executa, o como se vive, enfim.

É importante mencionar que ao longo dos anos em que adotamos o Index em nossas pesquisas, a dimensão de políticas não apenas se refere à infraestrutura de apoio à inclusão, mas também às intenções, em geral explícitas, que têm por objetivo guiar e orientar as práticas (sejam elas culturais, políticas ou de ação propriamente ditas). Na verdade, a partir do Index, temos desenvolvido uma perspectiva de análise dos fenômenos sociais e humanos intitulada de omnilética (SANTOS;SANTIAGO, 2013; SANTOS, 2013). Esta perspectiva incorpora as três dimensões, e em adição admite que elas se encontram entrelaçadas por relações ao mesmo tempo dialéticas (MESZAROS, 2013) e complexas (MORIN, 2011). Neste sentido, trazer o desafio intelectual da junção de um pensamento moderno com um supostamente pós-moderno, é um dos desafios da perspectiva omnilética.

Nossa proposta principal é despertar o potencial protagonista da ação docente para a elaboração de estratégias pedagógicas próprias, que, intencionalmente, promovam o debate, a identificação e a valorização das diferenças, assim como a eliminação das barreiras à inclusão em educação. No ano de 2015, o OEERJ realizou seu terceiro Ciclo de Formação, no qual os professores elencaram cinco temas a serem desenvolvidos no processo de formação: acessibilidade, currículo, avaliação, formação docente e políticas públicas. Para cada tema, buscamos identificar indicadores no Index que pudessem contribuir com a formação dos participantes durante o Ciclo e em suas escolas. O Ciclo ofereceu 12 encontros, e foi intitulado Ciclo de Formação de Professores para a Inclusão do Público-alvo da Educação Especial - refletindo, planejando e agindo.

Este Ciclo, em especial, foi coroado de sucessos ao final. Em parte, porque desta vez conseguimos a participação de alguns professores de salas comuns juntos com os de AEE, um desafio, até então, importante e difícil de ser alcançado, segundo nossos dados desde o primeiro Ciclo de Formação (2012). A modificação de culturas e práticas de vários professores foi notável, o que nos motivou a continuar com o Observatório Estadual.

Assim, em 2016, utilizamos o primeiro semestre para tratar e analisar os dados de 2015, produzir escritos sobre a experiência e planejar o Ciclo seguinte, que iniciou em julho de 2016 e intitulou-se Ciclo de Formação sobre a Diversidade em Sala de Aula: 
desenvolvendo culturas, políticas e práticas de inclusão. Resumidamente, até o presente, podemos dizer que, entre os achados marcantes de cada Ciclo estão, no primeiro, uma enorme lacuna de comunicação entre professores de sala comum e de AEE. No segundo, não apenas reforçou-se este achado como também se trouxe à tona a perspectiva de que a classe de professores precisava se mobilizar mais e trabalhar colaborativamente. $O$ terceiro Ciclo, por sua vez, deixou bem claro que a formação docente tem sido negligenciada no que tange aos cinco temas eleitos pelos participantes, e que isto deveria ser uma preocupação constante dos órgãos públicos, mas, também, das universidades (públicas ou privadas). De forma exploratória, apresentaremos as cinco temáticas neste artigo.

Procederemos à análise por tema, tendo em vista a complexidade de cada um e as “sutilezas” que se entrelaçam, dialética e complexamente, em termos culturais, políticos e práticos, ora facilitando, ora obstaculizando, um processo educativo orientado pelos princípios de inclusão. Ressaltamos que nossa análise segue a perspectiva omnilética, conforme exposto acima. Vale esclarecer que estas categorias foram construídas a partir da técnica da análise de conteúdo (BARDIN, 2011) com base em todo o material gravado em vídeo e áudio, que, após cada encontro, era transcrito. A equipe de pesquisadores procedeu, em conjunto, à leitura de todo o material organizado em um grande Bloco de dados e, a partir de discussão e análise, construíram códigos e categorias para cada tema investigado. Isto feito, realizamos nova leitura do material, agora organizado por categorias e unidades de sentidos.

\section{Acessibilidade}

Nesta categoria, obtivemos dados que apontaram para preocupações diversas e intrigantes. Pudemos reagrupar os depoimentos em algumas unidades de sentidos, a saber: Acesso à Informação, a Recursos, à Tecnologia, à Comunicação, Acesso Físico, Atitudinal e Direito ao Acesso.

De todas as narrativas relativas à acessibilidade, o acesso a recursos foi a mais comum. É notório perceber que pessoas oriundas de diferentes municípios do Rio de Janeiro manifestaram o mesmo descontentamento: o de que não há recursos (humanos, 
tecnológicos, físico-espaciais...) ou, quando há, não são equitativamente distribuídos, seja entre as escolas, entre os profissionais na escola, ou entre os alunos da escola. $O$ excerto abaixo é emblemático:

O acesso é muito restrito, pois os alunos não utilizam a biblioteca regularmente, nem os recursos. Isso também já foi discutido aqui. Precisa ter uma pessoa na sala de recursos ou na biblioteca para que os alunos possam utilizar. (BLOCÃO_OEERJ2015_ 22 DE JANEIRO_PDF. [154:2591154:2832])

Entendemos que a falta de acesso aos recursos disponíveis se estabelece como mais uma barreira com a qual os professores se deparam. Ou seja, ainda que recursos importantes, como uma biblioteca, estejam “disponíveis”, a falta de alguém responsável pela sua administração diária torna o seu uso inviável. Muitas vezes, a falta de pessoal se soma ao medo de roubos nas instalações escolares e a necessidade de manter o espaço trancado. Nessas circunstâncias, para a instituição, ter bibliotecas ou laboratórios de informática ou ainda, material para educação física adaptada, guardados e trancados, não influencia positivamente na formação dos alunos.

Na esteira da falta de acesso a recursos, o acesso (ou falta de acesso) à tecnologia foi uma unidade de sentido fortemente evocada, mesmo que os atuais projetos de lei em discussão no campo da educação (por exemplo, as Bases Nacionais Comuns Curriculares) enalteçam imensamente o uso das tecnologias, seja por parte dos alunos, seja pelos profissionais da educação. Neste sentido, a pergunta que não cala é: como requerer a generalização do uso destas ferramentas quando não se tem como adquiri-las?

Mesmo com o acesso à tecnologia sendo estimulado nas políticas públicas de educação, no cenário das escolas do Rio de Janeiro, poucas são as que possuem rede wi-fi de internet, ou laboratórios de informática disponíveis à comunidade escolar. Em muitos casos observados, os computadores encontram-se com programas ultrapassados e fora de uso, aguardando reparos técnicos.

Destacamos ainda, o acesso à informação, que se trata de um dos maiores recursos e uma das maiores barreiras à inclusão. Uma instituição pode cercear as informações, tomar decisões de forma hierarquizada, designar, mandar, decretar. Outra 
pode tratar as informações de forma transparente, consultar, sugerir, horizontalizar, propor.

\begin{abstract}
Ofertar para esses profissionais o acesso às legislações vigentes sobre acessibilidade e inclusão, porque os nossos profissionais, eles não conhecem, os nossos professores de sala regular, eles não têm esse acesso que nós, professores de AEE temos, sobre as legislações, sobre o processo de inclusão, e qual é a primeira justificativa deles quando nós chegamos para propor alguma coisa? Você que é especialista, quem fez especialização foi você, eu não fiz... E o nosso projeto, ele visa acabar com esse discurso, na nossa unidade, você não tem uma especialização em educação especial, mas agora você tem acesso, você tem acesso à legislação, você tem acesso ao processo de inclusão, como ele ocorre... (BLOCÃO_OEERJ2015_22 DE JANEIRO_PDF. [266:2099-266:2339])
\end{abstract}

A questão atitudinal constituiu uma unidade de sentido pertinente à acessibilidade, pois frequentemente, as barreiras são criadas inteiramente dentro do ambiente na forma de atitudes e práticas discriminatórias e a não remoção dos obstáculos ao acesso e à participação (BOOTH e AINSCOW, 2011, p. 42). Isto significa que, o acesso atitudinal supõe o desenvolvimento de novas práticas que suportem e acolham a comunidade escolar.

Uma instituição sensível aos princípios da inclusão busca preparar, informar, trabalhar com sua comunidade as questões relativas ao seu cotidiano. Se para algumas, criar grupos de estudo e discussão sobre a legislação vigente é necessário, para outras, conhecer e conversar com profissionais de saúde sobre alguns problemas cognitivos comuns ao contexto escolar pode ser vantajoso para toda a comunidade. O que não se pode aceitar é que se fechem os olhos para as demandas institucionais, culpabilizando as possíveis vítimas.

\title{
Avaliação
}

A avaliação tem sido o "calcanhar de Aquiles" do processo de inclusão em educação. Os principais aspectos da avaliação que pudemos destacar concentram-se em torno das seguintes unidades de sentido: Avaliação Diagnóstica, Autoavaliação, Avaliação 
Clínica, Concepção de Avaliação e Estrutura para a Avaliação. Vejamos os exemplos a seguir.

Pensar sobre a concepção de avaliação, de imediato nos remete a duas vertentes principais: investigação ou exame. São dois paradigmas distintos que denotam processos de inclusão/exclusão, na medida em que operam com a ideia de diferenças interpretadas como deficiências ou assumem as diferenças como particularidades a serem exploradas. A transcrição abaixo associa currículo à avaliação, metaforizando o "olhar" como possível recurso para compreensão dos diferentes processos e concepções que envolvem a avaliação:

(...) então falar de currículo e de avaliação é falar também de olhar, qual é o olhar que você está conseguindo ter desse currículo? Que tipo de avaliação seu olhar te permite fazer? Às vezes é importante mudarmos o olhar, de repente você está olhando, mas não está enxergando, então olhe mais um pouco e veja mais profundamente. (BLOCÃO_OEERJ2015_ 22 DE JANEIRO_PDF.[323:2092-324:667])

O olhar atento e interessado nos sujeitos constrói uma concepção de avaliação mais detalhada e cuidadosa, capaz de considerar elementos que uma mirada geral descartaria.

Ainda nos remetendo à função dos diferentes olhares sobre a avaliação, nos acercamos do conceito de autoavaliação, prática específica de professores pesquisadores, que cotidianamente exercem uma prática reflexiva. Na transcrição abaixo, a professora questiona sua própria prática de forma crítica, não culpabilizando o aluno, demonstrando que o resultado do aluno está relacionado com sua prática pedagógica, ou seja, o ensino-aprendizagem e a avaliação são processos indissociáveis.

Se a gente tem um cantinho na sala e se a atividade não está sendo legal, funciona também como fuga, ele não está fazendo o que está sendo proposto para ele e ele simplesmente vai te enrolar, e vai lá pegar, não estou achando legal, não vou conseguir fazer e não atingi, aí aonde vem a nossa reflexão, a nossa práxis, se realmente eu estou alcançando o meu aluno. Estou falando a mesma linguagem que ele? Se o meu conteúdo está adequado à situação da vivência dele? O cognitivo dele? Ele está acompanhando? Será que realmente o que eu estou passando 
para ele, ensinando, todo dia nessa turma que está todo dia conosco? Será que ele realmente está aprendendo? (BLOCÃO_OEERJ 2015_ 22 DE JANEIRO_PDF. [83:1947-83:3290])

Somente o exercício da autoavaliação possibilitará que o professor estabeleça uma relação de interdependência com o aluno, com a prática pedagógica, com o contexto e as barreiras envolvidas no processo.

A avaliação diagnóstica produz pistas importantes sobre o processo de ensinoaprendizagem, pois indicam quais conhecimentos estão presentes nas respostas dos alunos, que desconhecimentos demonstram, que tipo de ação o professor deve tomar para auxiliar a aprendizagem, de que novos conhecimentos necessitam. Enfim, esta etapa da avaliação serve, objetivamente, para criar estratégias e intencionalidades pedagógicas que superam as barreiras à aprendizagem e à participação dos alunos.

\begin{abstract}
A gente recebe da escola, a gente tem uma ficha de encaminhamento, é um instrumento onde a escola vai colocar os dados da criança, e o que a escola já fez pela criança. Como é que a criança está com o seu raciocínio lógico? Que nível de letramento a criança se encontra? Quais foram as intervenções que a escola fez com a criança? Quais foram as intervenções que a escola fez com esses pais? E aí a gente recebe e faz. Chama as crianças e esses pais para fazer avaliação. Os pais assinam um termo de responsabilidade para poder a criança ficar ali com a gente durante 0 período, porque não é um serviço ambulatorial. (BLOCÃO_OEERJ2015_ 22 DE JANEIRO_PDF [167:4494-168:548])
\end{abstract}

A afirmação de que o atendimento educacional especializado não é um serviço ambulatorial, é especialmente relevante quando se trata da Educação Especial, pois muitas vezes a avaliação diagnóstica assume o caráter de aquisição de laudo médico ou avaliação clínica, em virtude do modelo médico de deficiência ainda presente na concepção de alguns profissionais, pais e educadores. Na transcrição abaixo, vemos um exemplo desta tendência em transição para o modelo social de deficiência:

Então nós começamos com 39 alunos da educação especial, numa proposta de laboratório com esses 39 alunos. E aí, qual foi o objetivo que a gente passou para esse trabalho? Avaliação de profissionais de saúde, 
apesar do psicólogo e da fono também serem considerados profissionais da educação, mas naquele momento eram profissionais de saúde, faziam uma avaliação clínica deles, para que a gente pudesse entender um pouco mais desse aluno para pensar intervenções que pudessem dar esse suporte pedagógico para as escolas. (BLOCÃO_OEERJ2015_ 22 DE JANEIRO_PDF. [167:1659-167:2217])

Nesta perspectiva, a avaliação clínica em caráter multidisciplinar oferecerá recursos, que na concepção da professora, poderão auxiliar nas intervenções pedagógicas.

Outro aspecto da avaliação que merece nossa atenção se direciona à avaliação de larga escala que não é adaptada e nem considera os diferentes ritmos e condições de aprendizagem de cada aluno.

Nós sabemos que julho está chegando, teve a primeira avaliação do SAERJ, e que a gente tem parceria com o estado e que ele precisava fazer essa avaliação do nono ano. Eu tenho uma deficiência intelectual incluída, na mesma sala eu tenho dois surdos e uma Síndrome de Down, na mesma escola, no nono ano e tenho avaliação externa. E a avaliação externa não é adaptada. Como é que eu faço isso com ele? (BLOCÃO_OEERJ2015_22 DE JANEIRO_PDF. [196:3713-197:207])

Não questionamos a importância ou a necessidade da avaliação institucional nem em larga escala, mas precisamos construir culturas, políticas e práticas avaliativas pautadas nos processos de ensino-aprendizagem e nas singularidades dos alunos e não exclusivamente orientadas pelos resultados. O processo de inclusão requer a promoção de condições de superação de barreiras à aprendizagem e à participação, e neste sentido a avaliação tem sido um constante desafio a esse princípio, conforme os relatos de experiência das professoras.

\section{Currículo}

Nesta categoria, observamos que os professores participantes do Ciclo de 2015 elegeram os seguintes aspectos como centrais: Engessamento, Extensão, Flexibilidade Curricular e Tipo de Currículo. 
No que tange à flexibilidade curricular é necessário problematizar as seguintes questões: Que objetivos desejamos alcançar? O que ensinar? Que valores estão implícitos nos objetivos? Por que ensinar determinado conteúdo e não outro? Que recursos favorecem a aprendizagem e a participação de todos os alunos? A transcrição abaixo se reporta a tais reflexões e explicita a produção do currículo a partir dos interesses e questionamentos dos alunos, sem desconsiderar conteúdos e saberes formais:

(...) a escola que eu estava tinha um laboratório de informática bom e tinha uma parceria legal com o monitor de lá e a gente foi ver como eram os raios, enfim, eu terminei fazendo um projeto para aquela turma e depois não só ele trazia uma pergunta, toda semana tinha o dia da pergunta, onde cada um trazia uma pergunta que quisesse e a gente ia tentando responder ao longo da semana, e aí todos os alunos, até que chegou uma menina com o rosto queimado de cigarro, e todo mundo falou: "o que foi isso?" - e ela falou: "a minha mãe me queimou com o cigarro". E a gente foi pesquisar. O trabalho deles era saber quantas crianças tinham na família pessoas que fumavam, por que fumavam e a gente lia aquelas notícias e foi preparando material e como é que ficava o pulmão de quem fumava e foi muito legal, porque as crianças no final da aula, cada dia a gente ia colando numa parte e trabalhando aquilo, e elas levavam para os familiares e aí falavam: "oh, mãe, seu pulmão vai ficar daquele jeito" e foi um trabalho muito legal. Então, esse é um trabalho que é permitido na educação infantil, porque nós temos um currículo muito flexível, e disponibilidade também para estar trabalhando com alguns recursos. (BLOCÃO_OEERJ2015_ 22 DE JANEIRO_PDF. [86:76486:2047])

A flexibilidade curricular possibilita que as demandas atuais do contexto institucional sejam abordadas junto com os alunos e também com a própria escola, que toma conhecimento do que está acontecendo em sua comunidade, podendo tomar providências quando necessário.

Entretanto, a despeito do relato anterior, a questão do engessamento curricular é tema recorrente entre as professoras que, em alguns contextos, se sentem constrangidas e limitadas ao uso de material didático e apostilas, que resultam em aulas expositivas e pouco interativas:

As crianças são encorajadas a dizer quando não entendem? Aí, a gente colocou que no geral não, nossa vivência. As aulas são preparadas para 
serem, em sua maioria, expositivas, pela praticidade e no dia a dia, aquela correria. As aulas são mais preparadas para ser de exposição. Na maioria, o currículo é engessado, assim como a professora falou aqui hoje, as apostilas e tal. (BLOCÃO_OEERJ2015_ 22 DE JANEIRO_PDF. [91:18191:580])

Quando consideramos a importância de um currículo flexível e nos deparamos com uma realidade oposta, de engessamento, indagamos: como as demandas institucionais podem ser abordadas se os currículos e as propostas estão pré-definidos?

Outra questão a ser superada se refere à extensão do currículo, ou seja, grande volume de conteúdo a ser ministrado em determinado tempo. Esse processo dificulta a construção de proposições mais colaborativas e contextualizadas, uma vez que os professores se sentem ameaçados pelas avaliações que 'cobram' determinadas habilidades e competências dos alunos, desconsiderando suas reais necessidades e dificuldades:

E na hora de preparar as aulas, não são previstas as dúvidas dos alunos. E com um currículo extenso e as avaliações que a gente sempre recebe, essa semana foi de avaliações lá na escola, e falta tempo para desenvolver os conteúdos, com diferentes estratégias para atender à diversidade dessa turma, fatores que podem levar os alunos a não sanarem as suas dúvidas. (BLOCÃO_OEERJ2015_ 22 DE JANEIRO_PDF. [91:582-91:978])

Currículos extensos em conteúdos dificultam a participação dos alunos e criam barreiras à aprendizagem destes. É fundamental que o planejamento considere espaço para as discussões em sala de aula, para as interferências dos alunos, para as demandas e combinados do grupo. Um currículo fechado negligencia toda esta riqueza que favorece a criação do sentido no ato de aprender.

Durante as discussões sobre currículo ficou evidenciada a necessidade de superar barreiras relativas à homogeneização curricular, aos processos avaliativos que selecionam e classificam os alunos em uma perspectiva que despreza os tempos e os ritmos individuais. 


\section{Formação Docente}

No que tange à formação dos professores, muitas foram as queixas, como também muitos foram os depoimentos de experiências bem-sucedidas. Em termos de unidades de sentido evocadas e discutidas, destacamos as seguintes: Formação Limitada, Formação em Contexto, Política e Gestão da Formação Continuada, Motivação para a Formação e Impactos da Formação oferecida pelo OEERJ.

O contexto educacional é dinâmico e, muitas vezes, imprevisível. Por isso, presenciamos com alguma constância falas como as que estão descritas abaixo, de desabafo. Como estar preparado para tudo? Que professor, por melhor formação que tenha, estará preparado para os desafios da educação atual: Drogas, violência, transtornos, questões culturais, de gênero, de racialidade?

Vale dizer que, com a mesma constância, presenciamos a manifestação de professores que buscam superar os desafios que encontram "sentando" com seus alunos e descobrindo juntos a melhor maneira de ensiná-los. Talvez este seja o conhecimento de experiência feita, freiriano em essência, que poderá trazer as respostas que tanto procuram.

Gente, então dá para a gente sentir aquela coisa do preparado, o que é estar preparado, né? Quem está preparado? E a colega teve a curiosidade, teve a boa vontade, teve o relacionamento afetivo de... Quê que eu vou fazer para o meu aluno participar das atividades? É isso que faz falta, é lógico que capacitação, estudo, formação, faz falta, mas a questão primordial é eu ver essa coisa... Se o aluno não está trabalhando, eu tenho que incentivar algo, senão, que educador é esse? Não precisa nada de luxo, nem ser caro, precisa sentar com aquela criança e alguma coisa ele tem que fazer, alguma coisa eu... ele tem que produzir e testar com você. (BLOCÃO_OEERJ2015_ 22 DE JANEIRO_PDF. [263:421263:1127])

Entre questionamentos e necessidade contínua de formação, as professoras destacam que a formação no contexto da própria escola tem especial relevância, pois possibilita a identificação de barreiras para que, de forma coletiva, possam ser superadas. Esta ideia constitui a base do que defendemos como formação em uma perspectiva omnilética, que envolve a articulação das dimensões de culturas, políticas e práticas de 
inclusão em educação, considerando as contradições e complexidade que envolvem este processo.

O processo formativo oferecido pelo ciclo, embora não aconteça na escola, dialoga com a escola. Acreditamos que isto tem se tornado um diferencial que pode ser confirmado através dos relatos e reconhecimentos das professoras participantes:

Nós temos o professor itinerante que tem por obrigação orientar o professor, mas o professor itinerante visita a nossa escola uma vez por mês, então quem vai oferecer esse suporte? É o professor de AEE, e agora toda a comunidade escolar, o que nós propomos à nossa comunidade é não ter mais essa desculpa: o itinerante vem uma vez por mês, e agora, o quê que eu vou fazer? Não, você tem acesso, você sabe o que é a paralisia cerebral, você sabe o que é a Síndrome de Down, então, o que você pode fazer? Vamos sentar, vamos conversar, a nossa equipe pedagógica, ela não tem nenhuma formação sobre inclusão, sobre deficiência, elas relatam que alguns anos atrás em sua formação, elas não tiveram esse reconhecimento, e o nosso Projeto trouxe para elas também o acesso, as legislações, os principais autores, o Index, e isso auxiliou e muito. (BLOCÃO_OEERJ2015_ 22 DE JANEIRO_PDF. [268:2123269:166])

A narrativa evidencia a importância do processo de formação continuada para o desenvolvimento profissional e o acesso ao conhecimento de leis, orientações, referenciais teóricos que precisam ser discutidos para revigorar ou transformar as práticas. Essa experiência formativa tem se afirmado como instrumento que viabiliza troca de experiências entre diferentes escolas e tem proporcionado motivação entre as professoras, no que tange à construção de culturas, políticas e práticas pedagógicas que podem contribuir para redimensionar a escola como um todo.

\section{Políticas Públicas}

Por fim, mas nem por isso menos importante, as discussões ao longo do Ciclo referentes ao tema das políticas públicas apontaram a necessidade de continuidade nas políticas, recursos para propiciar implementação das políticas, suporte para a melhoria do trabalho docente, políticas institucionais/pedagógicas e políticas como construção coletiva. Apontaram, ainda, contradição entre a política formulada e sua implementação. 
As professoras consideram a importância do envolvimento de toda a comunidade escolar nas decisões de caráter político, tanto nos aspectos administrativos como nos aspectos pedagógicos para possibilitar e garantir a continuidade das ações e implementação das políticas, como se pode constatar no relato seguinte:

O que a gente estava discutindo aqui, foi em relação a uma política que deve envolver toda escola, porque se eu acredito nesse trabalho, e trabalho o ano todo e acaba o ano letivo e o outro colega não acredita nisso, então, praticamente, tudo aquilo que você trabalhou cai por terra. (BLOCÃO_OEERJ 2015_ 22 DE JANEIRO_PDF. [157:1459-157:1762])

A percepção da política como produção sociocultural e não como mera imposição vertical demonstra a formação crítica de algumas participantes, que ao se considerarem sujeitos no processo de efetivação da política no contexto educacional, nos remetem à perspectiva freiriana de que a educação é ato político, promove mudanças e intervenções em contextos diversos e adversos:

Uma coisa que eu aprendi no curso é que as políticas públicas não são aquilo que somente vem de lá, de um lugar diferente, que a gente nem sabe aonde é muitas das vezes, e a gente também pode colaborar para que essa política aconteça... E por mais que a gente não veja assim, tudo assim sendo feito da maneira como deveria... Nós somos também partes dessa política, e nós colocamos a nossa mão... Mão na obra, mão na massa... BLOCÃO_OEERJ 2015_ 22 DE JANEIRO_PDF. [322:1020322:1480])

Verificamos a concepção de que inclusão está associada às dimensões de políticas, culturas e práticas, pois romper com barreiras historicamente afirmadas, no que diz respeito à exclusão das diferenças no contexto educacional, envolve mudança de paradigma, ou seja, precisamos mudar nosso modo de ver e de estar no mundo.

A inclusão escolar está diretamente relacionada com suas políticas pedagógicas, cultural e social. Esse movimento junto torna possível a interação de crianças público-alvo da Educação Especial junto com crianças sem necessidades especiais vivendo no mesmo ambiente escolar, aprendendo junto e respeitando as diferenças né... (BLOCÃO_OEERJ 2015_22 DE JANEIRO_PDF. [94:48-294:405]) 
Diferença não é deficiência. Converter diferenças em oportunidades educacionais é um ato político. No que se refere à temática política, a questão de maior importância no decorrer do ciclo de formação, consistiu na afirmação das políticas como construção coletiva e em assumir que na educação não existe neutralidade, ou seja, que nossas culturas e práticas são, também, políticas.

\section{Considerações provisoriamente finais}

Quando analisamos fenômenos da vida com a lente omnilética, torna-se muito difícil chegar a conclusões no sentido comumente atribuído à palavra, em uma acepção de certeza ou de finalização. Assim, mesmo quando conseguimos fazê-lo, não há como considerá-las finais, tampouco elas garantem, embora estejam adequadas, que tal adequação seja uma certeza que se estenda para situações semelhantes em contextos e tempos diferentes. Na melhor das hipóteses, podemos apresentá-las como provisórias, temporárias, tantas são as culturas, políticas e práticas possíveis de serem identificadas e em jogo dialético e complexo. Neste sentido, nossas conclusões podem ser consideradas mais como novas hipóteses originadas da experiência com a formação, por meio das trocas com nossos brilhantes colegas da rede Básica, a quem, aliás, agradecemos imensamente a parceria.

Procedendo então às conclusões, podemos dizer que os cinco temas eleitos já são, em si mesmos, relevantes de serem considerados, na medida em que, no contexto deste estudo, representaram as principais preocupações dos professores colaboradores. $\mathrm{Na}$ lente omnilética, acesso, avaliação, currículo, formação e políticas são considerados como categorias que, entendidas em uma totalidade (o contexto da pesquisa, seus sujeitos, suas bagagens), refletem culturas, políticas e práticas simultaneamente em consenso, dissenso, em um entretecimento dialético e complexo.

Assim, se iniciarmos nossa análise pelo acesso, podemos ver que este depende de políticas públicas, mas sua garantia na prática não pode prescindir de uma avaliação e currículo talhados para as diferenças que se apresentam na escola, sejam elas as comumente reconhecidas como "minorias", sejam elas ainda invisíveis. Ademais, colocar este currículo e avaliação em prática depende de uma formação, seja ela inicial ou 
continuada, e estas estão, por sua vez, relacionadas às políticas públicas e à própria demanda social pelo acesso, cuja luta se dá pelos movimentos sociais representativos dos grupos excluídos.

Por outro lado, ao iniciarmos a mirada omnilética pela categoria avaliação, percebemos que ela se atrela a uma necessidade de contemplar aquelas diferenças que têm obtido acesso à escola, assim como a uma concepção curricular que democratize as relações entre saberes e práticas, considerando a atual formação que se tem, enquanto almejando a formação que se deseja. O que, por sua vez, liga-se às políticas públicas, sem as quais torna-se complicado avaliar, garantir acesso, planejar o currículo e formar-se em uma orientação de inclusão.

O exercício omnilético analítico poderia também se iniciar pela categoria currículo, e aqui apontaríamos a forte relação que o tema mostrou no que tange tanto à formação docente quanto à avaliação e ao acesso, pois estas “forçariam” o repensar da própria concepção curricular adotada pela instituição, a qual, por sua vez, segue diretrizes curriculares, que não deixam de ser políticas públicas.

O início de nossa análise pela categoria da formação profissional, igualmente, nos remeteria a tecer uma relação desta com as outras categorias. As políticas públicas, por exemplo, em particular as atuais, conclamam as universidades, cada vez mais, a proverem esta formação, seja em nível inicial, seja por meio de ações de parceria e extensão para a formação continuada. As instituições que assumem esta iniciativa, por sua vez, provavelmente já estariam trabalhando com concepções curriculares e de avaliação com orientações inclusivas, o que, por outro lado, implicaria uma preocupação com a acessibilidade.

Por fim, se iniciarmos a análise pelas políticas públicas, podemos ver que, ao longo da história, elas tanto têm influenciado quanto sido influenciadas pelas práticas de ensino, avaliação e curriculares, assim como pelos movimentos em favor de uma maior acessibilidade educacional. Por conta deste movimento, temos obtido, em nossa história, políticas tanto consideradas 'progressistas' quanto 'retrógradas'.

Mesmo tecendo todas estas relações, nenhuma delas nos dá uma certeza de que a vida assim vista, nesta tessitura de totalidades em novas totalidades, daria "certo". Mas 
este mesmo reconhecimento da incerteza nos coloca no esforço de tecer novas relações, ora priorizando uma categoria, ora outra, como mote inicial de busca de soluções (provavelmente temporárias) de problemas e de tomadas de decisões. E isto abre portas antes não vistas como possíveis, ou sequer imaginadas, o que é muito positivo.

No que tange ao protagonismo e autonomia dos professores, a eleição dos temas demarcou um dos seus aspectos, bem como as análises que iam tecendo ao longo do curso a respeito das temáticas escolhidas, que também atestam este movimento emancipatório, conforme visto nos depoimentos apresentados.

Portanto, para finalizar provisoriamente, reforçamos a importância do exercício de olhar cada totalidade por diferentes ângulos em suas relações complexas e dialéticas. Neste exercício, vamos elegendo, sempre coletivamente, prioridades temporárias que gerem novas análises e ações culturais, políticas e práticas que, sempre em movimentos de contradição e complexidade, surtem novas totalidades. Estas, por sua vez, num movimento contínuo, seriam retomadas omnileticamente em suas subtotalidades, dando continuidade às transformações que a vida nos impõe, cotidianamente. 


\section{Referências}

BARDIN, Laurence. Análise de conteúdo. São Paulo: Edições 70, 2011.

BOOTH, Tony; AINSCOW, Mel. The Index for inclusion: developing learning and participation in schools. London: CSIE, 2011.

MÉZAROS, István. O conceito de dialética em Lukács. 1 ed. São Paulo: Boitempo, 2013.

MORIN, Edgar. Introdução ao pensamento complexo. Porto Alegre: Sulina, 2011.

SANTOS, Mônica Pereira dos. Dialogando sobre inclusão em educação: contando casos (e descasos). Curitiba: CRV, 2013.

SANTOS, Mônica Pereira; SANTIAGO, Mylene Cristina. Ciclo de formação de professores sobre inclusão em educação: em direção a uma perspectiva omnilética. In: REUNIÃO NACIONAL DA ANPED $36^{\text {a }}$ - Goiânia / GO, 2013. Anais... Disponível em:

<http://36reuniao.anped.org.br/pdfs_trabalhos_aprovados/gt15_trabalhos_pdfs/gt15_290 1_texto.pdf>. Acesso em 28 de julho de 2016.

Universidade do Estado de Santa Catarina - UDESC

Programa de Pós-Graduação em Educação - PPGE

Revista Linhas

Volume 19 - Número 39-Ano 2018 revistalinhas@gmail.com 